\title{
Development of utilization systems for forest residue in Hokkaido according to a Japanese strategy for a sustainable society
}

\author{
S. Mori, T. Furuichi \& K. Ishii \\ Graduate School of Engineering, Hokkaido University, Japan
}

\begin{abstract}
The Japanese government has a strategy for achieving a sustainable society by integrating three societies: low carbon, a sound material-cycle, and natural symbiosis. In particular, biomass utilization is critical for achieving a sustainable society. The utilization of forest residues, which form part of the unused biomass, is expected to occur, and the target utilization ratio of forest residues is $>30 \%$ by 2020 . However, the current utilization ratio is $1 \%$. It is necessary to clarify the relationship between the utilization of forest residues and the implementation of the three societies above, and to promote the strategic utilization of forest residues, particularly in Hokkaido, as it has abundant forests. Therefore, in this study, the relationship between the utilization of forest residues and the three societies was clarified regarding its effect and limitations according to the Japanese strategy for a sustainable society. Problems in the utilization of forest residues in Hokkaido were then extracted systematically by carrying out a hearing survey of specialists in Hokkaido. Based on the problems encountered, we have developed a feasible system for utilization of forest residues in Hokkaido.
\end{abstract}

Keywords: sustainable society, forest residue, modeling, hearing survey.

\section{Introduction}

The Japanese government has proposed "The 21st Century Japanese Environmental Strategy", which aims to achieve a sustainable society by integrating three societies: low carbon, a sound material cycle, and natural symbiosis [1]). On the other hand, the utilization of biomass is now being promoted in Japan. The utilization of biomass contributes to a low-carbon 
society from the reduction in $\mathrm{CO}_{2}$ to be carbon neutral, to a sound material cycle society because it is an unused resource, and to a natural symbiosis society because it is an organic resource derived from living things. Therefore, the utilization of biomass is a proper and critical factor in terms of achieving a sustainable society.

Forest residues are one type of biomass that is expected to be utilized more often. Forest residues are presently a rarely used biomass, with a utilization ratio of only $1 \%$, although they have a huge energy potential. However, the "Basic plan of the promotion of biomass utilization", which was newly decided by the Cabinet Council of Japan, aims for a utilization ratio of forest residues of $>30 \%$ by 2020 [2]). Therefore, an effective and concrete plan for forest residue utilization is a pressing need.

The relationship between the utilization of forest residues and the integration of the three societies has not been clarified, and therefore it is necessary to clarify these relationships, and to consider forest residue utilization as an important policy towards the integration of the three societies. In particular, the role of Hokkaido, which has about a quarter of Japan's forests, is large, and the immediate practice of forest residue utilization is necessary.

The promotion of the utilization of forest residues in Hokkaido towards a sustainable society is the overall purpose of this study. The objectives of this study are as follows:

(1) To clarify the relationship between forest residue utilization and the three societies.

(2) To extract the topics for utilization of forest residues in Hokkaido, paying particular attention to the relationship to the three societies by carrying out a hearing survey with experts in Hokkaido.

(3) To propose a feasible model for the utilization of forest residues in Hokkaido based on the extracted topics.

\section{Effort and topics towards forest residue utilization}

\subsection{Present condition and topics of forest residue utilization in Japan}

The amount of forest residues generated per year is eight million tonnes [2]), and most of it is not utilized, remaining in the forest after thinning. One of the main reasons is the cost of its collection. Therefore, it is necessary to provide the basic infrastructure used for its collection, for example, providing a road network in the forest and developing highly efficient heavy equipment. It is also necessary to build the collection and transportation system at a low cost and high efficiency. Moreover, concerning the methodology of forest residue utilization, the development and demonstration of utilization methods, assistance in the development of woody biomass boilers, and the promotion of forest residue fuels for use in coal-fired power plants are required. 


\subsection{Effort in Hokkaido}

In Hokkaido, the aim is for the entire volume of unused wood generated in the area, including forest residues, to be utilized by 2017. The purpose of the plan is to increase the added value of the woody material of Hokkaido. In particular, the target for increasing the quantity of energy utilization of forest biomass, which is composed of forest residues, remnants material from sawmills, and material from wooden buildings, is set to increase from $34,000 \mathrm{~m}^{3}$ in 2006 to $67,000 \mathrm{~m}^{3}$ in 2017 [3]). An active effort is being pursued towards achieving this target, for example, developing working models of a high-efficiency forest residue collection system.

\section{Extraction of topics of forest residue utilization in Hokkaido based on a hearing survey}

\subsection{Necessity of a systematic viewpoint}

The requirement for building a forest residue utilization system is: (0) to clarify the purpose of the utilization, and to combine (1) input (collection of forest residues), (2) output (utilization methodology), (3) conversion technology (transportation and conversion), and (4) implementing body, considering (5) the regional characteristics, for accomplishing the purpose of utilization. Therefore, the topics of forest residue utilization of Hokkaido were extracted from the viewpoint of the system shown in stages (0) to (5) in Figure 1.

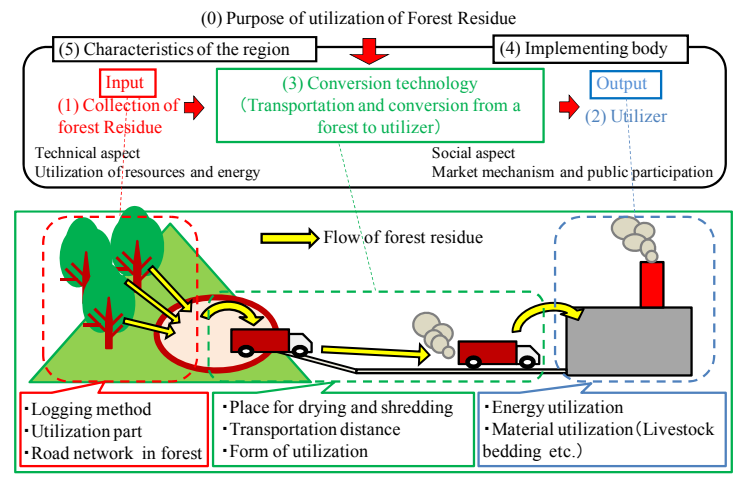

Figure 1: A systematic viewpoint of forest residue utilization.

\subsection{Objects of the hearing survey}

Centering on the main forestry management organizations, five groups were targeted (Ashoro town, Hokkaido Forestry Experiment Station, the Iwakura Co. Ltd, the Hokkaido Agency Forestry Section, and the Eastern Part of the Tokachi Forest Management Office). 


\subsection{Subjects for setting the purpose of forest residue utilization}

The setting of a purpose of forest residue utilization is closely related to the forest management body and the management purpose of the forest, and the utilization situation also differed greatly according to the management purpose of the forest. Therefore, the subject of the purpose setting and each system element was extracted according to the management body involved.

Municipal and private forests were targeted in this study, although "national forest" and "prefectural forest" are mainly used in the text here owing to space restrictions. Table 1 shows the subjects in a purpose setting.

Table 1: $\quad$ Subjects for setting the purpose of each forest management body.

\begin{tabular}{|c|c|c|c|c|}
\hline & $\begin{array}{c}\text { National } \\
\text { forest }\end{array}$ & $\begin{array}{c}\text { Prefectural } \\
\text { forest }\end{array}$ & $\begin{array}{c}\text { Municipal forest } \\
\text { (Ashoro town) }\end{array}$ & Private forest \\
\hline $\begin{array}{c}\text { Purpose of } \\
\text { forest } \\
\text { management }\end{array}$ & \multicolumn{2}{|c|}{ conservation $\gg$ utilization } & $\begin{array}{c}\text { conservation> } \\
\text { utilization }\end{array}$ & $\begin{array}{c}\text { conservation< } \\
\text { utilization }\end{array}$ \\
\hline $\begin{array}{c}\text { Present } \\
\text { purpose of } \\
\text { forest residue } \\
\text { utilization }\end{array}$ & $\begin{array}{c}\text { Forest } \\
\text { cleaning } \\
\text { (forest } \\
\text { conservation) }\end{array}$ & $\begin{array}{c}\text { No } \\
\text { utilization }\end{array}$ & Local development & $\begin{array}{c}\text { Improvement of } \\
\text { business }\end{array}$ \\
\hline
\end{tabular}

\subsubsection{National forest}

Only the forest residues that can be easily collected and gathered in a timber yard in a forest are being utilized by selling them. However, the Japanese government, which is the national forest management body, assumes forest conservation is the primary purpose, and an environmental impact is also reduced to contribute towards a low-carbon society and a natural symbiosis society, because a sound forest is formed from the promotion of thinning and removing the forest residues from the forests. Forest residue utilization should be set as an aim of forest management in addition to forest conservation.

\subsubsection{Prefectural forests}

In the prefectural forests of Hokkaido, the utilization of forest residues is not currently being performed. However, forest residue utilization should be the aim of forest management in addition to forest conservation, because the Hokkaido prefecture, which is the management body of the prefectural forests, has the same aims for forest residue utilization as the national forests.

\subsection{Subjects for input}

Table 2 shows the subjects for input into our model. This also explains what part of the forest residue is used. As shown in Figure 2, the forest residue can be divided into three use parts based on the different parts where it is generated: "mill ends" generated from unused trunks, "treetop" generated from the edge of the treetops, and "branch" generated from branches and leaves. As shown in Figure 3, the quantity generated by the "branch" is much larger than the other two parts. 
Table 2: $\quad$ Subjects for input for each forest management body.

\begin{tabular}{|c|c|c|c|c|}
\hline & National forest & Prefectural forest & $\begin{array}{l}\text { Municipal forest } \\
\text { (Ashoro town) }\end{array}$ & Private forest \\
\hline $\begin{array}{c}\text { Utilization } \\
\text { part }\end{array}$ & $\begin{array}{c}\text { Mill ends at the } \\
\text { side of timber yard }\end{array}$ & No utilization & Mill ends & All parts \\
\hline $\begin{array}{l}\text { Logging } \\
\text { method }\end{array}$ & Short trunk logging & Full tree logging & $\begin{array}{c}\text { Mainly tree length } \\
\text { logging }\end{array}$ & \multirow{3}{*}{$\begin{array}{c}\text { Related to } \\
\text { scale of } \\
\text { undertaking } \\
\text { body }\end{array}$} \\
\hline $\begin{array}{c}\text { Road network } \\
\text { in forest }\end{array}$ & \multicolumn{2}{|c|}{ Transition to the high density road net } & $\begin{array}{c}\text { No advance of road } \\
\text { net equipment }\end{array}$ & \\
\hline $\begin{array}{l}\text { Undertaking } \\
\text { style }\end{array}$ & $\begin{array}{l}\text { Automation with } \\
\text { high efficiency } \\
\text { heavy equipment }\end{array}$ & $\begin{array}{l}\text { Transition to } \\
\text { automation }\end{array}$ & $\begin{array}{l}\text { Using standard } \\
\text { heavy equipment } \\
\text { or man power }\end{array}$ & \\
\hline $\begin{array}{l}\text { Final cutting } \\
\text { or thinning }\end{array}$ & \multicolumn{2}{|c|}{ Mainly thinning } & $\begin{array}{c}\text { Related to the } \\
\text { characteristics of } \\
\text { the region }\end{array}$ & $\begin{array}{l}\text { Mainly final } \\
\text { cutting }\end{array}$ \\
\hline
\end{tabular}

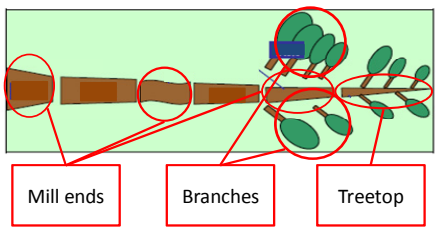

Figure 2: $\quad$ Utilization parts of forest residues.

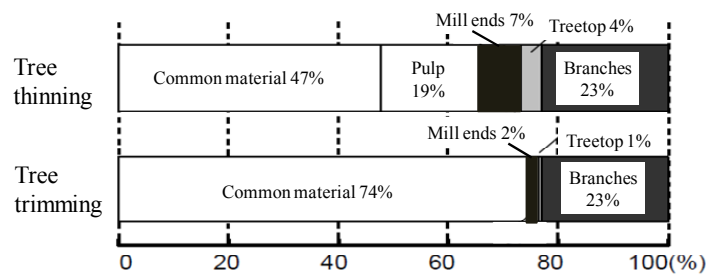

Figure 3: $\quad$ The ratio of the amount of biomass generated for full trees [4]).

The logging method is also defined. As shown in Figure 4, there ${ }^{\text {are }}$ three types of logging method: "full tree logging", "tree length logging", and "short trunk logging". Both the full tree logging and tree length logging methods need consideration for forest conservation, as dragging timber over long distances can

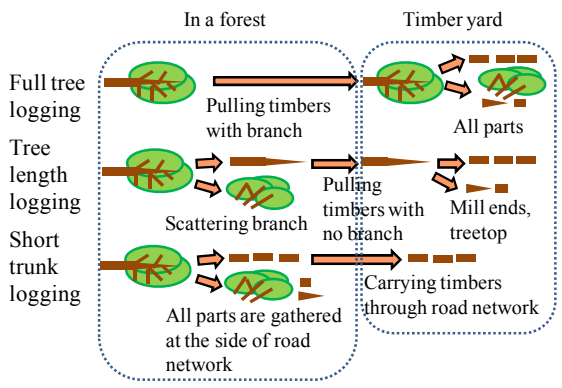

Figure 4: Relationship between each logging method and utilization. 
lead to environmental loading. In particular, full tree logging causes much environmental loading to a forest from dragging timber with side branches.

On the other hand, short trunk logging can have a low environmental loading, because it uses heavy equipment for carrying. However, for example, the mechanization of operations and the preparation of a road network in the forest are required for performing short trunk logging, and so a capital investment threshold is required for an organization to consider performing such logging.

When the logging method is considered from the viewpoint of forest residue utilization, full tree logging can be easily carried out in a forest for all parts of the forest residue, because branches accumulate at a timber yard in a forest. It is difficult for tree trunk logging to include branches, because the branches become scattered in the forest, and the mill ends and treetops are gathered at the timber yard. In short trunk logging, the forest residue stays in the forest, but for much of the time, forest residue is gathered at the side of the road network in neat piles. Heavy equipment is required to collect the forest residue gathered at the side of the road network, and this involves the cost needed to operate and drive the heavy equipment.

\subsubsection{National forest}

The maintenance of a forest is being performed by proper thinning. However, the amount of utilization is limited at the mill ends, and the timber yards only rarely utilize forest residues as a material, and the remaining mill ends and treetops and the branches gathered at the side of the road network are being left in the forest.

\subsubsection{Prefectural forests}

The logging method needs to be reconsidered, because full trunk logging has been the subject of forest conservation, and currently, there is no utilization with respect to forest residues because of the difficulty in securing profitability. However, some of the residues generated should be utilized, as with the case of the national forests.

\subsection{Subjects for the output}

Table 3 shows the subjects for the output. In the national forests, the mill ends at the side of timber yards are utilized as material for livestock bedding or moisture control agent for compost. However, some of the residues should be utilized as energy resources towards a low-carbon society. Moreover, material utilization is meaningful for forming a natural symbiosis society to contribute to food

Table 3: $\quad$ Subjects for the output of each forest management body.

\begin{tabular}{|c|c|c|c|c|}
\hline & National forest & $\begin{array}{c}\text { Prefectural } \\
\text { forest }\end{array}$ & $\begin{array}{c}\text { Municipal } \\
\text { forest } \\
\text { (Ashoro town) }\end{array}$ & Private forest \\
\hline Output & $\begin{array}{c}\text { Material utilization } \\
\text { (livestock bedding } \\
\text { etc.) }\end{array}$ & $\begin{array}{c}\text { No } \\
\text { utilization }\end{array}$ & $\begin{array}{c}\text { Mainly energy } \\
\text { utilization }\end{array}$ & $\begin{array}{c}\text { Energy utilization } \\
\text { Material utilization }\end{array}$ \\
\hline
\end{tabular}


production, and if the compost produced is applied properly, it will contribute to forming a sound material cycle society.

\subsection{Subjects for conversion technology (transportation and conversion)}

Table 4 shows the subjects for the conversion technology. A forestry road as described here indicates a road in the forest where the timber yard and a general road are connected. Maintenance of the pavement of a forestry road is important to improve the efficiency of the forest industry.

Table 4: Subjects of the conversion technology of each forest management body.

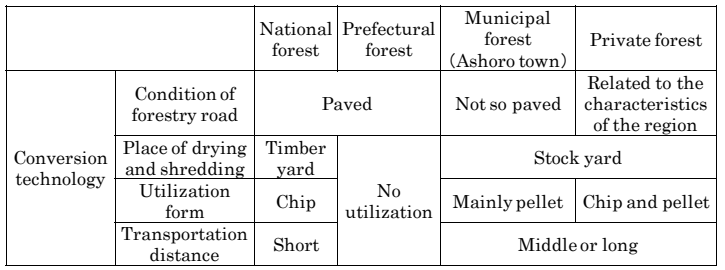

A place of drying and shredding is where shaking off loose soil and adjusting the moisture content of the forest residues over a set period occurs, because, as a rule in energy utilization, attached soil and any excess moisture in the residues can lead to a reduction in the thermal efficiency or impose a burden on the burning appliance or the shredding equipment. The requirement for a drying process differs depending on the demands of the end user. For example, in material utilization, some soil and moisture are permitted.

The place for drying and shredding will be at the timber yard or the chipping factory. Because the residues are transported from a forest as wood chips, the transport efficiency of shredding in the timber yard will be high, which means that truck usage can be reduced. However, there are limited ways to select utilization methods, because the chips generated through a "nondrying" process will incorporate much soil and moisture. On the other hand, drying and shredding of the residues in the chipping factory will affect the transportation efficiency and consume fossil fuels, because the forest residues will be transported as is. Therefore, a method of improving the transportation efficiency is required, e.g., an ability to align the forest residues for carriage.

The distance from the utilizer means the distance from the timber yard or the chipping factory to the utilizer. It is necessary to consider the consumption of fossil fuels, because the amount of their consumption increases with distance. However, the requirements for acceptance of forest residues differ according to the utilizer, and to distribute forest residues on a large scale, pellets made from the forest residues will enable it to be sold with a high efficiency. Therefore, in consideration of these matters, it is necessary to estimate the validity of the transportation distance from the viewpoint of an effective reduction in $\mathrm{CO}_{2}$ emissions. 
In the national forests, some forest residues are shredded into chips at the timber yards while in a forest, and this is transported to local livestock farmers. This method is rational in the present circumstances. However, some of the forest residues that will be collected in the future should be utilized as energy resources, and so it will be necessary to reconsider the process for drying and shredding. Moreover, from the viewpoint of an effective reduction in $\mathrm{CO}_{2}$ emissions, it is hoped to examine using forest residues in a large boiler facility located a medium or long distance away, in consideration of the characteristics of the region.

\subsection{Subjects for the implementing body}

Table 5 shows the subjects for the implementing body. The implementing body of the forest residue utilization is classified into two types: "single enterprise" and "cooperative society". The single enterprise type is a business where a single enterprise performs the collection, transportation, processing, and selling of the forest residues gathered in a timber yard. On the other hand, a cooperative society type is a business where a cooperative society organized by individuals or small and medium-sized enterprises perform the collection to the selling.

Table 5: Subjects for the implementing body of each forest management body.

\begin{tabular}{|c|c|c|c|c|}
\hline & $\begin{array}{c}\text { National } \\
\text { forest }\end{array}$ & $\begin{array}{c}\text { Prefectural } \\
\text { forest }\end{array}$ & $\begin{array}{c}\text { Municipal forest } \\
\text { (Ashoro town) }\end{array}$ & Private forest \\
\hline $\begin{array}{c}\text { Implementing } \\
\text { body }\end{array}$ & $\begin{array}{c}\text { Single } \\
\text { enterprise } \\
\text { type }\end{array}$ & $\begin{array}{c}\text { No } \\
\text { utilization }\end{array}$ & $\begin{array}{c}\text { Cooperative society } \\
\text { type }\end{array}$ & $\begin{array}{c}\text { Single } \\
\text { enterprise } \\
\text { type }\end{array}$ \\
\hline
\end{tabular}

Presently, in the national forests, the business form is the single enterprise type where a company selling livestock bedding purchases forest residues shredded at the timber yard, and then transports and sells the residues to livestock farmers. The demand for livestock bedding tends to be more than the supply. Moreover, it is anticipated that this trend will become more marked, as the national policy is to target increased food self-sufficiency. Therefore, it is expected that the present business form will continue, but some of the forest residues from the national forest should be utilized as an energy resource; furthermore, because the national forest management body has admitted the availability of forest residues for energy utilization, the business management of forest residues for energy utilization should be outsourced to the private sector. This should also occur for the prefectural forests that do not currently utilize forest residues.

\subsection{Subjects for the characteristics of the region}

To build an effective utilization system, it is required to consider the characteristics of the region in relation to the input, output, conversion technology, and implementing body factors. In particular, for the output and conversion technology topics, it is important to choose the correct option corresponding to the characteristics of the region. In a farming area, forest residues are utilized as an energy resource as a step towards achieving a low- 
carbon society and a sound material cycle society. On the other hand, some forest residues should also be utilized as livestock bedding as material utilization towards a natural symbiosis society, because the demand for livestock bedding or compost is high. Therefore, cooperation between both enterprises is required.

On the other hand, in an industrial area where there would be large biomass boilers, combustion with a high efficiency from forest residues gathered over a wider area than is now the case is expected to contribute towards a low-carbon society and a sound material cycle society. At that time, it will be important to consider the consumption of fossil fuels during transportation.

\section{Proposal for a feasible forest residue utilization model in Hokkaido for a sustainable society}

\subsection{Proposed forest residue utilization model for national and prefectural forests}

To clarify the relationship between forest residue utilization in the national and prefectural forests and the formation of a sustainable society, a feasible forest residue utilization model based on incorporating the topics for each of the system elements is proposed, and the relationships between the proposed model and three societies is considered. Figure 5 shows the utilization model of the national and prefectural forests.

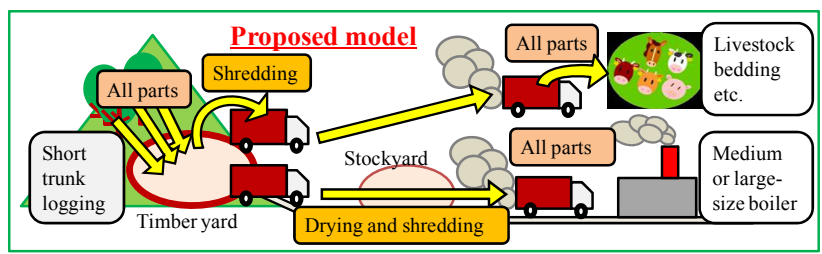

Figure 5: Utilization model for the national and prefectural forests.

\subsubsection{Setting purposes}

Presently, the national and prefectural forests perform forest management, which attaches importance to forest conservation. As part of this, only a low utilization of forest residues is being performed. However, because the national and Hokkaido prefecture forest management bodies wish to utilize unused forest residues, their utilization should be set as an aim of forest management in addition to forest conservation, and the scale of utilization should be increased to accomplish maximum forest residue utilization involving a reduction in fossil fuels consumption, $\mathrm{CO}_{2}$ emissions, and the promotion of sound forest formation.

\subsubsection{Input}

The input is set to achieve the purpose of maximizing the utilization of forest residues. In a forest, a reduction in forest-environmental loading and $\mathrm{CO}_{2}$ emissions is considered to be a maximum. Therefore, in a forest, short trunk 
logging using high-efficiency heavy equipment under low load will achieve this aim. Moreover, from the viewpoint of effective utilization of unused materials, the mill ends, treetops, and branches should be utilized as much as possible by collecting them from the side of the road network.

To implement the above low-load and higher-efficiency utilization, the road network in the forest should be established with a high density and be durable so that it can be used over the long term.

\subsubsection{Output}

Forest residues can contribute to a reduction of fossil fuels consumption directly by being utilized as an energy resource. Therefore, some of the forest residues generated should be utilized as an energy resource for this purpose. Moreover, from the viewpoint of an effective utilization of unused materials, the mill ends, treetops, and branches should be burned efficiently by using them in mediumsized or large boilers after drying and chipping, to utilize more residues than is the case presently.

On the other hand, the material utilization as livestock bedding, which occurs rarely at present in national forests, is important in terms of contributing to food production, and an increase in its demand is anticipated in line with the national policy, which is targeted towards increasing food self-sufficiency. Therefore, only some of the forest residues should be utilized for livestock bedding as material utilization. At this time, the proper spraying of the compost generated is required.

\subsubsection{Conversion technology}

In transportation, a reduction in $\mathrm{CO}_{2}$ emissions from trucks is required, and therefore, as material utilization, forest residues are mainly transported to local farmers. For energy utilization, they are also mainly transported to local combustion facilities, and this should be examined along with consideration of $\mathrm{CO}_{2}$ emissions from transportation to larger boilers located at medium to long distances according to the characteristics of the region. To implement a highly efficient transportation system, increasing the loading density per unit in a truck is important, and an advanced device to load the residues is required.

In the drying and shredding process, the residues for energy utilization require a drying process, and therefore these are dried and shredded in a stockyard. The residues for material utilization do not require a drying process. Therefore, they are presently shredded in a timber yard.

\subsubsection{Implementing body}

Energy and material utilization are set by each implementing body. In material utilization, business management in the present form is expected to continue because of increasing demand. Therefore, the business management of utilization is performed by selling the residues from a forest management body to a private enterprise. 
On the other hand, in energy utilization, the business management of selling the residues from a forest management body to a private enterprise is difficult, and the national and Hokkaido prefecture forest management bodies need to lead the expansion of the forest residue utilization. Therefore, the business management of the forest residue energy utilization should be performed by the national and Hokkaido prefecture bodies by outsourcing to the private sector.

\subsubsection{The characteristics of the region}

Especially for the output and conversion technology topics, it is important to choose the correct option corresponding to the characteristics of the region. In a farming area, the amount of material utilization increases with demand. In an industrial area where there is an existing large biomass boiler, the amount of energy utilization will also increase. A flexible response to the characteristics of a region is important for more utilization of the residues.

\subsection{Relationship between the proposed model and the three societies}

The input is short trunk logging using high-efficiency heavy equipment and the establishment of a high-density road network with good durability for forest conservation and reduced $\mathrm{CO}_{2}$ emissions while working in the forest. Collection and utilization of the mill ends, treetops, and branches gathered at the side of the road network in the forest will provide effective utilization of unused materials. Consequently, the reduction in $\mathrm{CO}_{2}$ emissions will contribute to a low-carbon society, the forest conservation will contribute to a natural symbiosis society, and the utilization of unused materials will contribute to a sound material cycle society.

In terms of the conversion technology topic, the transportation to local neighborhoods will reduce $\mathrm{CO}_{2}$ emissions during transportation. Therefore, a reduction in $\mathrm{CO}_{2}$ emissions during transportation can be regarded as a limitation to the low-carbon society.

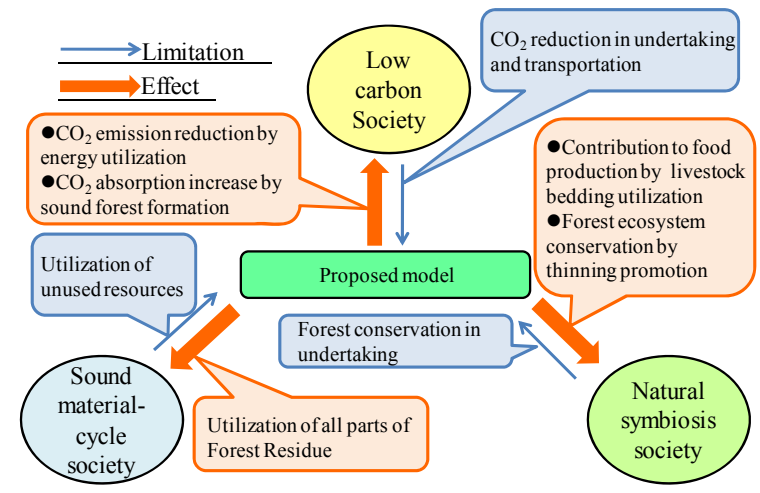

Figure 6: Relationship between the proposed model and the three societies. 
In the output topics, the material utilization of livestock bedding contributes towards a natural symbiosis society by contributing to food production. The energy utilization from using residues in a biomass boiler contributes to a lowcarbon society by reducing $\mathrm{CO}_{2}$ emissions from a carbon neutral point of view. The maximum utilization of all parts of the forest residues contributes to a sound material cycle society from the effective utilization of unused materials. Moreover, the promotion of thinning from forest residue utilization contributes to a natural symbiosis society by conserving the forest ecosystem and to a lowcarbon society by increasing the amount of $\mathrm{CO}_{2}$ absorbed by forming a sound forest. These can be regarded as the effects on the three societies caused by utilizing forest residues. Figure 6 shows the relationships between our proposed model and the three societies.

\section{Conclusions and subjects for future study}

Three conclusions were obtained from this paper.

(1) The relationship between forest residue utilization and the three societies was clarified with regard to effect and limitations.

(2) The topics for utilization of forest residues in Hokkaido, especially paying attention to the relationship to the three societies, were identified from a hearing survey of experts in Hokkaido.

(3) A feasible utilization model of forest residues in Hokkaido based on the extracted topics was proposed for each forest management body.

Future subjects for study are follows.

(1) The relationship between the transportation distance and $\mathrm{CO}_{2}$ emissions has not been clarified.

(2) The permitted amount of soil and moisture in the combustion facility has not been clarified.

\section{Acknowledgements}

We wish to express our gratitude to everybody who cooperated with our investigation. Part of this study was funded by the Ministry of the Environment recycling society formation promotion science research expense subsidy of the H22 fiscal year.

\section{References}

[1] The Ministry of Environment, Japan: Becoming a leading environmental nation strategy in the 21st century, 2007, http://www.env.go.jp /en/focus/070606.html

[2] The Ministry of Agriculture, Forestry and Fisheries, Japan: Basic plan for promoting biomass utilization (in Japanese), 2010, http://www.maff.go.jp /j/biomass/b_kihonho/index.html 
[3] Hokkaido Prefecture: Basic plan for forest cultivation of Hokkaido (in Japanese), 2003, http://www.pref.hokkaido.lg.jp/sr/sum/kcs/r-g/r-keikaku /top.htm

[4] Meika Sakai: Toward effective biomass utilization, An investigation of the amount of woody biomass (in Japanese), 2004 http://www.fri.hro.or.jp /kanko/kiho/pdf/kiho133-4.pdf 